\title{
ANÁLISIS DEL CONCEPTO DE PARTICIPACIÓN EN LOS LIBROS DE FORMACIÓN CÍVICA Y ÉTICA DE $4^{\circ}, 5^{\circ}$ Y $6^{\circ}$ GRADO
}

\section{The CONCEPT OF PARTICIPATION IN ETHICS \& CITIZENSHIP IN 4TH, 5TH AND 6TH GRADE TEXT BOOKS ANALYSIS}

\section{Azucena de la Concepción Ochoa Cervantes azus@uaq.mx}

Currículo: doctora en Psicología. Docente de la Universidad Autónoma de Querétaro. Fundadora y responsable del Observatorio de la Convivencia Escolar de la misma universidad, miembro de la Cátedra Unesco de la Juventud, Educación y Sociedad y presidenta de la Red Latinoamericana de Convivencia Escolar. Dirige su investigación al estudio de la convivencia escolar a través de la promoción de la participación infantil en educación básica (primaria y secundaria).

\section{Felicia Vázquez Bravo}

felicia.vazquez@uaq.edu.mx

Currículo: doctora en Psiciología. Docente de la Universidad Autónoma de Querétaro. Sus líneas de investigación abordan la innovación y la gestión educativa, así como la educación para la ciudadanía.

Recibido: 12 de julio de 2017. Aceptado para su publicación: 5 de diciembre de 2017. Recuperado de: https://sinectica.iteso.mx/index.php/SINECTICA/article/view/770 DOI: 10.31391/S2007-7033(2018)0050-011

\section{Resumen}

La presentación del conocimiento escolar en el nivel básico se hace, por lo general, a través de los libros de texto, que son una parte evidente del currículo formal y, en muchas ocasiones, la pauta a seguir de las y los docentes. Existen estudios sobre este material desde diversos enfoques. En este trabajo analizamos la información que ofrecen los libros de 4ㅇ a 6으 grado de primaria de la asignatura de Formación cívica y ética acerca del concepto de participación, en el entendido de que la participación posiciona a niñas y niños como sujetos sociales. Realizamos un estudio descriptivo, con el método de análisis de contenido, que abarcó una muestra de tres unidades de análisis de los textos de la reforma educativa de 2011. Los resultados revelan el predominio de la dimensión política al abordar de manera reiterada la democracia como la forma de gobierno sustentada en una participación indirecta mediante la representación; de esto inferimos que la participación solo es válida en la medida en que esté dada con base en los mecanismos que la misma democracia establece. Lo anterior nos permite advertir contradicciones entre las competencias que se pretenden promover y la información presentada en este material.

Palabras clave: libros de texto, participación de niñas y niños, educación ciudadana.

\section{Abstract}

School knowledge in elementary level is presented through text books; these are part of the formal curricula, and a teacher's path to follow in several occasions. In our country many studies have been made regarding this matter, 
through different approaches. In this paper, our focus is to analyze the information about the notion of participation within 4th to 6th grade Citizenship text books, understanding that participation involves students as social subjects. Thus, a descriptive study was made with a content analysis method, based upon the analysis of extracts from three texts edited by the Secretariat of Public Education in Mexico. According to the previous study, the results show a predominance of a political dimension by repeatedly addressing democracy as a method of government supported by representation, which is given through indirect participation. Due to this analysis we can infer that participation is only valid under the mechanisms that said democracy establishes, and therefore we can realize the contradictions between the competencies that are expected to be learned and the information presented in the analysis sources.

Keywords: text book, children's participation, citizenship education.

\section{INTRODUCCIÓN}

or lo general, la presentación del conocimiento escolar se hace a través de los libros de texto, que son una parte evidente del currículo formal y, en muchas ocasiones, la pauta a seguir de las y los docentes, de tal forma que "su estructura es el punto de referencia de la secuencia temática que se sigue durante el año escolar" (Rockwell, 1997, p. 29). La estructura de la tarea académica gira en torno al libro de texto, que se convierte en lo que Pérez (1995) considera uno de los mecanismos de socialización en la escuela.

En nuestro país, los libros de texto, en particular los de historia y civismo, han sido objeto de investigación desde diversos enfoques. Encontramos los que abordan una perspectiva identitaria y la formación de nación (Vázquez, 1975; Corona y De la Peza, 2000); lo didáctico y el diseño pedagógico (De la Caba y López, 2005; Fierro, 2011); reconstrucciones históricas y debates (Villa, 2011); contenidos específicos como el racismo a través del análisis de imágenes (Corona y Le Mûr, 2016); la cultura de paz (Boqué, Pañellas, Alguacil y García, 2014); y la ciudadanía, desde la teoría del actor-red (Escudero y Farías, 2015).

Los aspectos abordados en estos estudios nos permiten inferir cómo se va construyendo un concepto a través del discurso que contiene dicho material. En este trabajo analizamos a la luz de la información que ofrecen los libros de Formación cívica y ética de 4으 a 60 grado de primaria el concepto de participación que se presenta en ellos, en el entendido de que la participación posiciona a niñas y niños como sujetos sociales con capacidad para expresar opiniones y decidir sobre asuntos que sean de su interés (Van Dijk, Menéndez y Gómez, 2006).

\section{LA FORMACIÓN CIUDADANA EN LA ESCUELA}

De acuerdo con el informe de Eurydice (2005), "la educación para la ciudadanía es uno de los medios principales mediante el cual los países europeos ayudan a los jóvenes a adquirir las competencias social y ciudadana que necesitarán en su vida futura" (p. 97), de forma que "está considerada como un instrumento para que niños y jóvenes se conviertan en ciudadanos responsables y activos" (p. 3). Esta educación debe incluir "el aprendizaje de los derechos y deberes de los ciudadanos, el respeto por los valores democráticos y por los derechos humanos, y la importancia de la solidaridad, tolerancia y participación en una sociedad democrática" (p. 3). 
La propuesta de inclusión de la formación ciudadana en los currículos escolares representa, a decir de Martín (2010), una mayor conciencia respecto de la importancia que tiene la formación para la participación y la convivencia en la educación de niños, niñas y adolescentes. Por ello, educar para la ciudadanía en las instituciones educativas refiere a la enseñanza de la participación de los estudiantes en los asuntos de las esferas pública e institucional (Bolívar, 2007), que debe preparar a los alumnos para la intervención activa en la sociedad, como elementos de cambio que propongan acciones encaminadas a mejorar su entorno social, político, económico y cultural (Gallardo, 2009); esto implica el formar parte de la vida de la ciudad y compartir deberes y obligaciones.

Para el Consejo de Europa (2004), la educación ciudadana es un conjunto de prácticas y actividades dirigidas a equipar a la ciudadanía joven y adulta con las herramientas necesarias para participar activamente en la vida democrática y asumir y ejercer sus derechos y responsabilidades sociales. Asimismo, considera que la educación ciudadana, basada en la promoción de la participación activa en todos los ámbitos de la vida social, es un elemento básico para la convivencia social (Bolívar, 2007), por lo cual se propone adecuarlo a las políticas educativas, en los planes de estudio de las escuelas y en la organización escolar.

De acuerdo con Chaux, Lleras y Velásquez (2004), todas las escuelas son formadoras de ciudadanos. La mayoría de las veces, la formación para la ciudadanía ocurre de manera implícita a través del currículo oculto, reflejado en las prácticas escolares y en la cultura del centro escolar; en otras ocasiones, se plasma en una materia obligatoria, como un enfoque trasversal, como parte de los programas de estudio o como uno de los objetivos de las políticas educativas de una nación (Marco, 2002). Sin embargo, a decir de Latapí (1993), la formación para la ciudadanía debe ser, además de una obligación estatal, un acto planificado e intencionado cuyo objetivo sea desarrollar la conciencia ciudadana y el sentido de responsabilidad social como componentes de la calidad de la educación, y dotar a los individuos de capacidades para participar y vivir en democracia.

En este sentido, las aproximaciones que existen a la educación ciudadana en el ámbito internacional se abordan desde cuatro modelos generales:

- La formación para la ciudadanía política: tiene como propósito la enseñanza de la ciudadanía a través de una asignatura específica de los currículos escolares. La formación del alumnado se basa en la comprensión del funcionamiento de las instituciones políticas del país con base en el modelo de la representatividad.

- La formación para una ciudadanía social: se basa en la incorporación de los derechos civiles, políticos, sociales, económicos, culturales y medioambientales para el desarrollo de la vida democrática. La finalidad de la formación ciudadana es que los alumnos puedan resolver problemáticas sociales analizando su impacto en la vida colectiva de la comunidad.

- La formación para la ciudadanía activa: en este modelo resulta fundamental la participación de la ciudadanía en los asuntos de la vida pública, e impulsar la responsabilidad social.

- La formación de la ciudadanía desde una postura crítica: en este modelo se pretende que los estudiantes cuestionen las posturas de 
la distribución del poder, así como las problemáticas sociales que afectan a los grupos en situación de vulnerabilidad (Cerda, Loreto, Magendzo, Santa Cruz y Varas, 2004, pp. 57-66).

En México, la formación para la ciudadanía puede ser agrupada en cinco enfoques formativos:

-Enfoque prescriptivo: se forma a partir de la asimilación de la información y la memorización de datos.

- Enfoque clarificativo: se profundiza en la reflexión y la objetivación de los valores a enseñar.

-Enfoque reflexivo-dialógico: en el que se pretende que los estudiantes identifiquen los valores en juego, reflexionen sobre ellos y definan una postura moral mediante la problematización de situaciones dilemáticas. - Enfoque vivencial: complemento del reflexivo-dialógico que amplía las situaciones dilemáticas en el contexto del aula y la institución escolar, lo que permite acercar las problemáticas del contexto a los estudiantes.

- Enfoque de construcción de la ética a través del servicio al otro: su premisa principal es dar un servicio en el ámbito escolar y la comunidad inmediata con la finalidad de propiciar en el alumnado la toma de decisiones y el uso de habilidades para la resolución de alguna problemática social (Schmelkes, 2011, pp. 102-105).

Así, la formación de la ciudadanía ha ido evolucionando en México a través de los distintos enfoques formativos y del paso del tiempo (ver tabla 1); actualmente, la asignatura de Formación cívica y ética es la materia desde la cual se aborda la formación ciudadana en la educación básica obligatoria.

Tabla 1. Cuadro comparativo de la formación ciudadana en la educación básica obligatoria de México

\begin{tabular}{|c|c|c|}
\hline Periodo & \multicolumn{1}{c|}{ Características } \\
\hline $1821-1871$ & $\begin{array}{c}\text { Formar ciudadanos con conciencia cívica y política del país (Tapia, 2003, p. } \\
\text { 21). La educación ciudadana es vista a partir del conocimiento de las leyes, } \\
\text { decretos y reglamentos del país. Es puramente legalista (Latapí, 2002) }\end{array}$ \\
\hline $1871-1910$ & $\begin{array}{c}\text { Etapa eminentemente positivista; la ciudadanía era entendida como el en- } \\
\text { salzamiento de los héroes nacionales, las batallas militares y las efemérides } \\
\text { de importancia nacional (Tapia, 2003, Latapí, 2002 y Álvarez, 1982). }\end{array}$ \\
\hline $1910-1943$ & $\begin{array}{c}\text { La educación social tiene el propósito de crear un ciudadano consciente } \\
\text { de su carácter mestizo con base en la identidad nacional como forma de } \\
\text { relacionarse en lo social. Se busca educar en valores y democracia (Tapia, } \\
\text { 2003), exaltando los valores nacionalistas, lo que pretendía integrar las he- } \\
\text { rencias hispana e indígena fundidas en un solo concepto que sirviera como } \\
\text { símbolo de unidad nacional. }\end{array}$ \\
\hline $1943-1970$ & $\begin{array}{c}\text { La educación ciudadana se basó en la enseñanza de valores patrióticos y en } \\
\text { el conocimiento de las leyes del país (Tapia, 2003). Se buscó fomentar las } \\
\text { virtudes cívicas e inculcar el amor a la patria (Gómez y Zurita, 2012). }\end{array}$ \\
\hline $1970-1993$ & $\begin{array}{r}\text { Desaparece de los planes de estudio la materia de civismo y sus contenidos } \\
\text { se engloban dentro de la materia de Ciencias sociales (Tapia, 2003). }\end{array}$ \\
\hline
\end{tabular}




\begin{tabular}{|c|c|}
\hline 1993-1999 & $\begin{array}{l}\text { La educación cívica apareció de nuevo como asignatura en los planes y pro- } \\
\text { gramas de primaria y secundaria, puesto que en México se vivía un proceso } \\
\text { de transformación en el que se fortalecieron la vigencia de los derechos } \\
\text { humanos, la democracia, el Estado de derecho y la pluralidad política. De } \\
\text { acuerdo con ello, la Secretaría de Educación Pública (SEP) consideró que } \\
\text { la educación básica requería abarcar cuatro aspectos centrales: formación } \\
\text { en valores; conocimiento y comprensión de los derechos y deberes; conoci- } \\
\text { miento de las instituciones y los rasgos principales que caracterizan la } \\
\text { organización política de México; y fortalecimiento de la identidad nacional } \\
\text { (Tapia, 2003, pp. 47-48). }\end{array}$ \\
\hline $1999-2006$ & $\begin{array}{l}\text { Proponía como base de la enseñanza el modelo ideológico democrático. } \\
\text { Los ejes de los cuales debía partir la enseñanza de la asignatura serían: } \\
\text { saber qué es la democracia; las habilidades o el saber hacer de la democra- } \\
\text { cia; y las actitudes o el ser y convivir democrático. Existe, igualmente, una } \\
\text { nueva visión de ciudadanía, la cual busca incorporar la vida cotidiana como } \\
\text { fuente de conocimientos de situaciones que le dieran sentido a las leyes, } \\
\text { valores y procedimientos, y se asocie a la resolución de los problemas de la } \\
\text { vida en la búsqueda de una mejor convivencia (Castellanos y Riveros, 1998, } \\
\text { citados en Conde, 2011, p. 18). }\end{array}$ \\
\hline $\begin{array}{l}2006 \text { a la } \\
\text { actualidad }\end{array}$ & $\begin{array}{l}\text { Basado en la Reforma Integral de Educación Básica, incorpora la dimensión } \\
\text { ética en la asignatura, así como el desarrollo de competencias cívicas a } \\
\text { través de todo el proceso de la educación formal. Busca superar el civismo } \\
\text { tradicional y fundamentar su aplicación en la ciudadanía activa basada en } \\
\text { el "respeto a la diversidad y la solidaridad, la responsabilidad, la justicia, } \\
\text { la equidad y la libertad, que cobran vigencia en el marco de una sociedad } \\
\text { plural” (SEP, 2011, p. 15). Se busca que el alumno, a lo largo del estudio de } \\
\text { la asignatura, adquiera y practique las siguientes competencias: conoci- } \\
\text { miento y cuidado de sí mismo; autorregulación y ejercicio responsable de } \\
\text { la libertad; respeto y aprecio a la diversidad; sentido de pertenencia a la } \\
\text { comunidad, la nación y la humanidad; manejo y resolución de conflictos; } \\
\text { participación social y política; apego a la legalidad y el sentido de justicia; y } \\
\text { comprensión y aprecio por la democracia (SEP, 2011, pp. 89-91). }\end{array}$ \\
\hline
\end{tabular}

Fuente: Pérez, 2017.

Como observamos en la tabla 1, la Reforma Integral de la Educación Básica y la entrada en vigor del Programa Integral de Formación Cívica y Ética para la Educación Primaria (Gutiérrez, 2007) representan un cambio de paradigma pedagógico en cuanto a la enseñanza de la formación ciudadana, debido a que se exige que, además de desarrollar conocimientos y actitudes, los estudiantes sean capaces de participar en un marco de democracia, poniendo en juego competencias y habilidades que les permitan insertarse en el mundo globalizado.

En efecto, el enfoque por competencias que define la asignatura de Formación cívica y ética marca un rompimiento con el paradigma tradicionalista de la enseñanza y exige que los alumnos, además de allegarse conceptos y datos de la materia, puedan integrar y articular "conocimientos, actitudes y habilidades en dispositivos que las y los alumnos puedan movilizar y activar para resolver los distintos desafíos y problemas que se les presentan en su vida cotidiana, tanto a nivel personal como social" (Gutiérrez, 2007, p. 19). 


\section{LA PARTICIPACIÓN COMO COMPONENTE CENTRAL PARA LA FORMACIÓN CIUDADANA}

Mokwena (1993) señala que la participación infantil repercute en la formación humana y ciudadana que se da en tres procesos. El primero indica que la participación es esencial para adquirir competencias y habilidades para el desarrollo de la confianza y la formación del carácter; el segundo tiene que ver con que la apertura de espacios de participación para niños y niñas permite formar un mayor compromiso consigo mismos, y genera un diálogo crítico, relaciones de respeto con los adultos y habilidades para resolver problemáticas y, por último, que la participación es un resultado del proceso de desarrollo del sujeto para la formación de identidad.

En la Convención sobre los Derechos del Niño (ONU, 1989), artículos 12, 13, 14, 15 y 26, y más recientemente en la Observación General número 12: "El derecho del niño a ser escuchado" (ONU, 2009), se plantea la intención de coadyuvar con los Estados parte para hacer efectivos los artículos mencionados de la citada convención, en los que se encuentra implícito el derecho a la participación. En dicha observación se apunta:

El concepto de participación pone de relieve que incluir a los niños no debe ser solamente un acto momentáneo, sino el punto de partida para un intenso intercambio de pareceres entre niños y adultos sobre la elaboración de políticas, programas y medidas en todos los contextos pertinentes de la vida de los niños (ONU, 1989, p. 13).

Aunado a lo anterior, en el mismo documento se hace hincapié en que los Estados parte deben observar el cumplimiento efectivo de este derecho en todos los ámbitos en donde la infancia crece y se desarrolla: familia, escuela, en situaciones lúdicas, en instituciones de salud, entre otros.

Si bien el establecimiento de instrumentos legales para la promoción de la participación infantil es una condición necesaria para ello, no es suficiente si se considera como el eje vertebral a partir del cual el ciudadano en formación aprende el ejercicio de los demás derechos.

El Menú de indicadores y sistema de monitoreo del derecho a la participación de niños, niñas y adolescentes proporciona una definición operativa de participación infantil al considerarla como proceso participativo en la medida que se hace efectivo el derecho de niños, niñas y adolescentes a ser informados, emitir opinión, ser escuchados e incidir en las decisiones que se toman respecto de temas que son de su particular interés e incumbencia, en los ámbitos familiar, judicial, educativo, de la salud, etcétera (OEA/INN, 2010, p. 21).

Este documento plantea que la participación constituye un derecho que se hace efectivo básicamente como un proceso comunicativo, organizativo y de aprendizaje en el cual se reconocen tres momentos: el primero se refiere a la información, la cual es un derecho en sí misma y una condición para que se dé la participación; por lo tanto, la fuente de información debe ser accesible, comprensible y de buena calidad, de modo que permita su apropiación por parte de niños, niñas y adolescentes. El segundo es el de construcción y reconocimiento de la opinión propia; en este se destaca que todas las opiniones, tanto individuales como colectivas, se construyen mediante la reflexión, la discusión, el intercambio, la síntesis y la reproblematización. Se dice que sin el reconocimiento de la voz propia (individual) no puede haber comunicación y, por lo tanto, no puede hablarse de participación. 
El tercero y último momento es el de expresión y escucha, en cuanto a que la libertad de expresión requiere instrumentos y manejo del lenguaje; además, se reconoce que, para que la expresión se concrete, es necesario que exista una escucha, la cual debe ser respetuosa y receptiva (OEA/INN, 2010, pp. 10-11).

Por otra parte, es necesario advertir que la participación no solo es un derecho que las instituciones deben resguardar y promover, sino que, en la escuela, este derecho debería ser además asumido como un proceso educativo que permite adquirir conocimiento, habilidades y valores necesarios para la formación de una ciudadanía activa.

\section{LA PARTICIPACIÓN COMO PROCESO EDUCATIVO}

Uno de los primeros autores que propuso una tipología para observar la participación de niños, niñas y adolescentes fue Roger Hart (1993), quien retomó la metáfora de una escalera para identificar los alcances de la participación de los niños en los proyectos comunitarios. En la escalera de ocho peldaños, el autor denomina a los tres iniciales como de no participación; a partir del cuarto y hasta el octavo iniciaría la participación propiamente dicha, y les denomina escalones de participación genuina. Para llegar a esta, el autor sugiere que la niñez debe estar informada, ser escuchada, ser consultada, dialogar para tomar decisiones, alcanzar consensos y compartir decisiones; es decir, asumir responsabilidades.

Por su parte, Trilla y Novella (2001) proponen una tipología tomando elementos de la propuesta de Hart (1993); plantean cuatro clases de participación de niños, niñas y adolescentes y cada tipo de participación puede admitir subtipos o grados, según la implicación, capacidad de decisión y responsabilidad. Su propuesta es la siguiente:

Participación simple, consistente en tomar parte de un proceso o actividad como espectador o ejecutante, sin que el niño o la niña hayan intervenido en su preparación ni en las decisiones sobre su contenido o desarrollo. Ellos solo se limitan a seguir indicaciones o a responder a estímulos.

Participación consultiva, que supone escuchar la palabra de niños y niñas, ya que estos no son meros espectadores, ejecutantes o usuarios de algo previa y externamente decidido, sino que se les demanda su opinión o parecer sobre asuntos que, de forma directa o indirecta, les conciernen. Se les invita a opinar, proponer o valorar, y se generan o facilitan los canales para ello.

Participación proyectiva, en la cual el proyecto también es del niño o niña; así se convierte en agente de cambio. Se trata de una participación más compleja, que puede ocurrir en las diversas fases del proyecto o de la actividad.

La metaparticipación, que consiste en que los propios niños pidan, exijan o generen nuevos espacios y mecanismos de participación, ya que piensan que el reconocimiento de sus derechos participativos no es el adecuado, o cuando creen que los canales establecidos para ella no son suficientes o eficaces.

Los mismos autores establecen tres condiciones para considerar la participación como real y efectiva: el reconocimiento del derecho a participar; el disponer de las capacidades necesarias para ejercerlo; y la existencia de medios o espacios adecuados para hacerlo posible (Trilla y Novella, 2001, pp. 145-151).

La Organización de Estados Americanos (OEA) especifica las condiciones para que se pueda hablar de procesos participativos: 
- Clima participativo: se describe como un clima agradable, de libertad y respeto que garantice que las opiniones sean tomadas en cuenta; así se eliminará toda posibilidad de ser intimidado o sancionado por ello. Se requieren habilidades por parte de niños, niñas y adolescentes, y sensibilización por parte de los adultos.

-Vínculo: se refiere a la relación entre dos o más personas en la que cada uno de los partícipes introduce imágenes producto de experiencias previas que interfieren en la comunicación, pero que ayudan a descubrir al otro.

-Encuentro: es necesario el encuentro con el otro (pares, adultos, instituciones, consigo mismo) para descubrir o redescubrir sus recursos, potencialidades y saberes.

- Oportunidad: las experiencias participativas constituyen una oportunidad de cambio en los mecanismos de discriminación y exclusión; también promueven reposicionamientos y nuevas formas para establecer relaciones con sus pares, intergeneracionales y con la comunidad.

-Aprendizajes significativos: los procesos participativos brindan un aprendizaje significativo a los niños, niñas y adolescentes cuando habilitan la reconstrucción de la forma en que las personas ven la realidad y se posicionan en ella (OEA/INN, 2010, p. 11).

Coincidimos con Novella (2011) en la idea de que, a través de la participación, las niñas y los niños tienen la oportunidad de construir su representación como personas autónomas con responsabilidades y competencias para poder definir sus proyectos personales y, de la misma forma, implicarse en los proyectos colectivos.

A partir de lo anterior, en este trabajo proponemos el análisis del concepto de participación desde dos connotaciones: como un derecho civil y político, y como un proceso educativo que permite integrar y articular "conocimientos, actitudes y habilidades en dispositivos que las y los alumnos puedan movilizar y activar para resolver los distintos desafíos y problemas que se les presentan en su vida cotidiana, tanto a nivel personal como social" (Gutiérrez, 2007, p. 19). Para hacerlo, proponemos, de acuerdo con Corona y Del Río (2005), analizar en los libros de texto la información relacionada con la participación del estudiantado en tres dimensiones: política, pedagógica y social-comunitaria, dado que estas nos permiten analizar el concepto a partir de las dos connotaciones mencionadas:

La dimensión pedagógica se refiere a las diversas formas de hacer partícipe al alumnado de su proceso de aprendizaje y evaluación; tiene que ver con la metodología de enseñanza y las formas en las que las y los docentes aseguran los aprendizajes.

La dimensión política concierne a las diversas formas y mecanismos que ayudan a los estudiantes a ejercer el derecho a participar en los asuntos que son de su interés o que les afectan.

La dimensión social-comunitaria se relaciona con las formas y mecanismos que permiten a los estudiantes ser actores sociales capaces de transformar su entorno.

Es pertinente aclarar que las dimensiones aquí propuestas no son excluyentes, sino complementarias.

Si la presentación del conocimiento escolar se hace conforme a lo que Rockwell (1997) denomina ritualización, y si el libro de texto es el punto de referencia de 
la secuencia temática durante el ciclo escolar, entonces se hace necesario indagar este material: por un lado, por ser la guía de las prácticas pedagógicas y, por otro, por el alcance que tiene al ser un material de distribución obligatoria y gratuita por parte del Estado.

Insistimos en que la escuela es el lugar idóneo para propiciar cambios en la sociedad, pues en ella se fomentan valores, actitudes y comportamientos, con lo que se promueve la participación y se genera una ciudadanía real y efectiva y, por ende, la construcción de una convivencia democrática.

\section{Metodología}

\section{Objetivo}

El objetivo de este trabajo es analizar el concepto de participación en los libros de texto de Formación cívica y ética de educación primaria, e identificar la presencia de ciertos componentes acordes con el concepto de participación, considerada como un proceso educativo.

\section{Tipo de estudio}

Es un estudio descriptivo, a través del método de análisis de contenido, entendiendo este como

toda iniciativa que, partiendo de un conjunto de técnicas parciales, pero complementarias, consiste en explicitar y sistematizar el contenido de los mensajes y la expresión de ese contenido con ayuda de indicios cuantificables o no. Todo ello con el objetivo de efectuar deducciones lógicas y justificadas concernientes a la fuente (el emisor y su contexto) -eventualmente los efectos- de los mensajes tomados en consideración (Bardin, 2002, p. 32).

Abarca una muestra de tres unidades de análisis de los textos de la reforma de 2011, correspondientes a los últimos tres grados del nivel de educación primaria de la asignatura de Formación cívica y ética. 
Tabla 2. Contenido temático de la materia Formación cívica y ética

\begin{tabular}{|c|c|c|c|}
\hline & $\begin{array}{c}\text { Formación cívica y } \\
\text { ética } \\
\text { cuarto grado }\end{array}$ & $\begin{array}{c}\text { Formación cívica y ética } \\
\text { quinto grado }\end{array}$ & $\begin{array}{c}\text { Formación cívica y } \\
\text { ética } \\
\text { sexto grado }\end{array}$ \\
\hline Bloque 1 & $\begin{array}{c}\text { Niños y niñas cuidan } \\
\text { de su salud e integri- } \\
\text { dad personal. }\end{array}$ & $\begin{array}{c}\text { Niños y niñas que cons- } \\
\text { truyen su identidad y } \\
\text { previenen riesgos. }\end{array}$ & $\begin{array}{c}\text { De la niñez a la adoles- } \\
\text { cencia. }\end{array}$ \\
\hline Bloque 2 & $\begin{array}{c}\text { El ejercicio de mi } \\
\text { libertad y el respeto a } \\
\text { los derechos propios y } \\
\text { ajenos. }\end{array}$ & $\begin{array}{c}\text { Niños y niñas que } \\
\text { aprenden a ser libres, } \\
\text { autónomos y justos. }\end{array}$ & $\begin{array}{c}\text { Tomar decisiones } \\
\text { conforme a principios } \\
\text { éticos para un futuro } \\
\text { mejor. }\end{array}$ \\
\hline Bloque 3 & $\begin{array}{c}\text { México: país diverso y } \\
\text { plural. }\end{array}$ & $\begin{array}{c}\text { Niños y niñas que traba- } \\
\text { jan por la equidad contra } \\
\text { la discriminación y por el } \\
\text { cuidado del ambiente. }\end{array}$ & $\begin{array}{c}\text { Los desafíos de las } \\
\text { sociedades actuales. }\end{array}$ \\
\hline Bloque 4 & México: país de leyes. & $\begin{array}{c}\text { Vida y gobierno demo- } \\
\text { crático. }\end{array}$ & $\begin{array}{c}\text { Los pilares del gobier- } \\
\text { no democrático. }\end{array}$ \\
\hline Bloque 5 & $\begin{array}{c}\text { La solución de conflictos } \\
\text { sin violencia y con apego } \\
\text { a los derechos humanos. }\end{array}$ & $\begin{array}{c}\text { Acontecimientos } \\
\text { sociales que deman- } \\
\text { dan la participación } \\
\text { ciudadana. }\end{array}$ \\
\hline
\end{tabular}

Fuente: SEP, 2014a, 2014b y 2014c.

\section{Procedimiento}

Identificamos y contamos los párrafos en los que se hacía mención explícita de la palabra participación (tanto en infinitivo como conjugada). La codificación del material se realizó utilizando el programa Atlas.ti, versión 1.5.1 para Mac solo como apoyo para identificar la palabra. Ubicamos la oración en la que se encontraba la palabra, y junto con el sentido de esta, del párrafo y la lección en la que se encontraba, clasificamos de acuerdo con las dimensiones señaladas en la tabla 3.

Tabla 3. Aspectos analizados en los textos

\begin{tabular}{|c|c|c|}
\hline $\begin{array}{c}\text { Dimensión de la parti- } \\
\text { cipación }\end{array}$ & \begin{tabular}{c} 
Información que la integra \\
\hline Dimensión política
\end{tabular} & $\begin{array}{c}\text { Se incluyeron las menciones que tienen que ver con derechos } \\
\text { humanos, derechos de los niños y las niñas, derechos vinculados } \\
\text { al derecho a la participación, mecanismos y formas de participa- } \\
\text { ción tanto en asuntos públicos como en cuestiones que son de su } \\
\text { interés o les afectan de manera directa o indirecta. }\end{array}$ \\
\hline Dimensión pedagógica & $\begin{array}{c}\text { Se incluyeron todas las menciones que hacen referencia a } \\
\text { acciones explícitas de enseñanza o aprendizaje que involucran el } \\
\text { término participación, así como las referencias a habilidades o } \\
\text { actitudes que se desarrollan con la participación. }\end{array}$ \\
\hline Dimensión social- \\
comunitaria & $\begin{array}{c}\text { Se incluyeron las menciones que hacen referencia a la participa- } \\
\text { ción mediante la interlocución con los miembros de la comuni- } \\
\text { dad, así como las menciones de la participación como una vía } \\
\text { para mejorar el entorno. }\end{array}$ \\
\hline
\end{tabular}

Fuente: elaboración propia. 
A partir de lo anterior, contabilizamos las apariciones de los términos en el discurso y, posteriormente, realizamos una interpretación del contenido con base en la consideración de la participación como un derecho o un proceso educativo.

\section{RESULTADOS Y DISCUSIÓN}

Los resultados se presentan por grado escolar y el análisis del término participación en relación con las dimensiones ya mencionadas:

\section{Cuarto grado}

Se encontraron 15 menciones del término participación, de las cuales 10 hacen referencia a la dimensión política, 3 , a la pedagógica y 2 , a la social.

Dimensión política

Las 10 menciones identificadas en esta dimensión aluden a las formas de participación legitimadas dentro del sistema democrático. Ejemplos:

En una sociedad tan grande como la nuestra es imposible participar todos de forma directa; nuestro sistema democrático permite la inclusión de diversos grupos sociales a través de representantes. Esta representación se logra por medio del voto y da como resultado autoridades que llevan a sus órganos distintos intereses y puntos de vista de los ciudadanos (SEP, 2014a, p. 81).

Tenemos derecho y obligación de elegir a las personas que nos representarán para tomar las decisiones de todos y gobernar, y de esta forma todos participamos en las decisiones (SEP, 2014a, p. 88).

Algunas menciones aparecen como parte de preguntas dirigidas al lector:

¿Conoces grupos de ciudadanos y ciudadanas que actúen unidos para enfrentar algún problema o asunto público? ¿Puedes mencionar algún problema o asunto público de tu comunidad que requiera que la ciudadanía participe y actúe para enfrentarlo? (SEP, 2014a, p.110).

En los ejemplos anteriores observamos que la información presentada tiene que ver, por un lado, con la legitimación de la participación a través de los mecanismos establecidos por la forma de gobierno del país y, por otro, que los niños y las niñas están invisibilizados, pues se desconoce que pueden participar al margen de las formas establecidas para los adultos. Es importante ampliar la mirada de la participación que puede y debe tener el alumnado, ya que es una falacia considerar que solo se puede participar de acuerdo con las formas establecidas. Coincidimos con Novella (2011) en la idea de que, con la participación, las niñas y los niños tienen la oportunidad de construir su representación como personas autónomas con responsabilidades y competencias para poder definir sus proyectos personales y, de la misma forma, implicarse en los proyectos colectivos; es decir, las y los ciudadanos se forman desde la infancia. 
Dimensión pedagógica

De acuerdo con el contenido de los párrafos, ubicamos acciones de enseñanza o aprendizaje que involucran el término, por ejemplo:

Sin duda, tu familia ha procurado que te alimentes bien para proteger tu salud y desarrollo. Ahora tu participación es muy importante, tú puedes decidir alimentarte sanamente y preparar alimentos sabrosos para llevar a tu escuela... (SEP, 2014a, p. 21).

Con ayuda de tu maestro o maestra, tu grupo puede escribir a niñas y niños de otra escuela, cercana o lejana, incluso de otro país. En la computadora puedes platicar con otros niños sobre cómo viven, qué estudian, cómo participan en su escuela y otros asuntos de su interés (SEP, 2014a, p. 24).

También ubicamos un párrafo en el cual la participación se relaciona con comportamientos o valores deseables: "La cooperación hace que se logren de mejor manera los proyectos que requieren esfuerzo, participación y recursos de dos o más personas..." (SEP, 2014a, p. 20).

De acuerdo con la tipología de Trilla y Novella (2001), el tipo de participación que se podría construir es simple, pues lo que se espera del alumnado es que sean solo espectadores o ejecutores de acciones; resulta preocupante no identificar en este libro información suficiente que permita construir ideas acerca de la participación como un derecho o como parte del desarrollo de los estudiantes.

La escuela es un lugar privilegiado de aprendizaje y desarrollo; en este sentido, esperaríamos que en los libros de texto se considerara desde lo pedagógico la importancia de la participación de los niños y las niñas para adquirir competencias y habilidades que logren un mayor compromiso consigo mismos y con los demás.

\section{Dimensión social-comunitaria}

Identificamos dos párrafos que contenían información relacionada con esta dimensión; cabe aclarar que los párrafos tienen también información de las otras dos dimensiones, sin embargo, haremos hincapié en la social-comunitaria:

La vida en sociedad requiere que todas las personas aporten un esfuerzo al bien común. En México han surgido diferentes formas de participación de las ciudadanas y los ciudadanos para enfrentar los problemas que nos aquejan y colaborar en el mejoramiento de la vida de nuestra comunidad. Cuando la ciudadanía trabaja en asuntos públicos de manera colectiva y con independencia del gobierno y los partidos políticos, se vale de la participación de la sociedad civil (SEP, 2014a, p. 110).

Tú podrás participar en proyectos para el mejoramiento social, económico y cultural de tu país, así como obtener más información y de mejor calidad, si conoces las instituciones encargadas de diversas tareas y servicios, así como en las leyes en las que se basan [...]. Para que tu participación sea eficaz, será útil que elabores un fichero con las instituciones de las que vas teniendo noticia. En este libro ya has conocido la labor de algunas. Aumentar esa información te ayudará a ejercer tu derecho a los servicios que ofrecen, así como tu derecho a obtener información de las labores de las autoridades y las instituciones públicas (SEP, 2014a, p. 116). 
Es interesante observar la referencia al mejoramiento de la comunidad a través de las acciones de la sociedad civil; sin embargo, la información que se presenta en estos párrafos es vaga, ya que en el primer ejemplo se habla de "otras formas de participación", pero no se ejemplifica cuáles o se describe alguna.

En el segundo ejemplo se indica que los lectores, esto es, el alumnado de cuarto grado de primaria, podrán participar en el mejoramiento de su país; no obstante, la forma de participación a la que alude es solo a través de un aumento de la información con la que se cuenta. Si bien es importante la información para ejercer la participación, para que se le considere como tal se tendría que hacer referencia a la construcción de una opinión, la emisión de esa opinión y las acciones derivadas de lo anterior.

La información que se presenta en el libro de cuarto grado de Formación cívica y ética en cuanto a la participación es parcial, ya que no se le alcanza a visualizar como un derecho ni mucho menos como un proceso educativo que permite la autonomía y responsabilidad de los individuos, tanto de manera individual como colectiva. Esto puede ser un factor que influya para que las ciudadanas y ciudadanos en formación construyan una visión acotada de la participación.

\section{Quinto grado}

Identificamos en diversos párrafos 20 menciones del término participación en su forma nominal, y en formas verbales no conjugadas y conjugadas con diferentes tiempos y pronombres (participación, participar, participa, participaba), de las cuales 16 se refieren a la dimensión política, una a la pedagógica, una que comparte rasgos de la pedagógica y la política, y dos de la comunitaria. Cabe señalar que en ese texto, al final de cada lección, hay una sección denominada "Participemos", en la cual se dan indicaciones a las niñas y los niños para realizar diversas actividades; estas menciones se analizarán como parte de la dimensión pedagógica debido a que se esperan ciertos aprendizajes a partir de dichas actividades.

\section{Dimensión política}

Al igual que en el grado anterior, las menciones encontradas hacen referencia a formas de participación por el sistema democrático, tal es el caso de la elección por medio del voto y la representación como forma de participación indirecta. Llama la atención que se incluye el pago de impuestos como un modo de participación responsable. A continuación presentamos algunos ejemplos:

La democracia es una forma de gobierno basada en la amplia participación de la ciudadanía, la toma de decisiones, la elección de los gobernantes y la elaboración de leyes. Antiguamente la ciudadanía participaba en forma directa mediante una asamblea, porque vivía en ciudades pequeñas y había pocos habitantes. Actualmente en México la democracia es representativa ya que, debido a la extensión de su territorio y a la cantidad de su población, sería imposible la participación directa. Por eso la ciudadanía elige mediante el voto a algunas personas, durante un breve periodo, sus gobernantes y representantes (diputados y senadores) y tomen decisiones en su nombre considerando los intereses y necesidades del pueblo que los eligió. Así la ciudadanía participa en las decisiones democráticas de manera indirecta (SEP, 2014b, p. 145). 
La manera como las personas que gobiernan llegan al poder, el modo de ejercerlo, de respetar los derechos humanos y la participación ciudadana permite determinar si un gobierno es democrático o no (SEP, 2014b, p. 146).

[La democracia] Es la forma de gobierno que favorece más claramente la participación ciudadana. Al ser un gobierno del pueblo, para el pueblo y por el pueblo, se establecen mecanismos para que la ciudadanía participe en la toma de decisiones sobre asuntos públicos, ya sea de manera directa o por medio de la consulta popular; o de manera indirecta por medio de representantes populares (SEP, 2014b, p. 147).

La participación ciudadana en las decisiones colectivas y en la solución de los asuntos públicos es uno de rasgos de la democracia. Una forma de participar es pagando impuestos de manera voluntaria (SEP, 2014b, p. 156).

Si bien en los ejemplos anteriores se describe la democracia como una forma de gobierno y como tal, la que está establecida en nuestro país, al hablar de participación y en el entendido de que los niños y las niñas son ciudadanos en formación, es cuestionable que ello no se asuma con mayor claridad, como se marca en el plan de estudios de la asignatura de Formación cívica y ética. Si la democracia es una forma de vida, sería deseable que se dejara ver en los textos que, en la escuela o en el entorno cercano al alumnado, para que se viva la democracia, sería necesario establecer las condiciones para que la infancia participe activamente en acontecimientos que los impulsen a poner en práctica los conocimientos, habilidades y actitudes "para resolver los distintos desafíos y problemas que se les presentan en su vida cotidiana, tanto a nivel personal como social" (Gutiérrez, 2007, p. 19).

Dimensión pedagógica

Solo identificamos una mención del término participación en esta dimensión:

Las personas adultas que te cuidan y te protegen toman decisiones relacionadas con el derecho a la salud. Por ejemplo, deciden qué comerá la familia o a qué servicio médico acudir y cuándo hacerlo. Tú puedes participar de manera responsable e informada en ésta y otras decisiones sobre tu salud. Para ello necesitas conocer tu cuerpo, tener conocimientos sobre una vida saludable, elegir alimentos nutritivos, comer a tus horas y hacer ejercicio. Éstas son acciones de las que puedes responsabilizarte (SEP, 2014b, p. 21).

Como mencionamos al inicio de la presentación de resultados de este grado, al final de cada lección existe un apartado titulado "Participemos". Estas menciones se ubicaron en la dimensión pedagógica dado que se espera que las niñas y los niños desarrollen actividades de aprendizaje.

El título es sugerente, pero, al analizar las actividades que se proponen, advertimos que, de las 20 propuestas, 16 (lecciones 1-3, 5-12, 14-15, 17-18 y 20) corresponden a lo que Trilla y Novella (2001) denominan participación simple, puesto que las actividades se limitan a intercambio de información o experiencias, exposición de trabajos elaborados previamente o a resolver o desarrollar la actividad propuesta en el apartado. La participación simple consiste en tomar parte de un proceso o actividad como espectador o ejecutante, sin que el niño o la niña hayan intervenido en 
su preparación ni en las decisiones sobre su contenido o desarrollo. Los niños solo se limitan a seguir indicaciones o a responder a estímulos. Esto podría propiciar que ellos construyan una noción de participación acotada y limitada a seguir las instrucciones de los adultos, como se ha mostrado en estudios anteriores (Ochoa, 2015; Castro, 2017; Pérez, 2017).

Las cuatro restantes $(4,13,16$ y 19$)$ podrían promover una participación consultiva o proyectiva; es el caso de la lección 4, en la cual se les pide que propongan ideas para eliminar la discriminación y promover el buen trato, o la lección 13, que plantea la puesta en marcha de una asamblea.

Llama la atención la lección 19, en la cual se explica que la participación puede ser social o política; allí el término se usa para decir que el hecho de que un ciudadano pueda participar lo convierte en un "emprendedor social", cuando lo que podría ser más adecuado es líder social o activista social, pues la palabra emprendedor remite al ámbito económico-financiero. En el apartado "Participemos" de esta lección se solicita que las niñas y los niños elaboren una iniciativa emprendedora para el bienestar, la seguridad y la convivencia en la escuela.

Dimensión social-comunitaria

En esta dimensión se localizaron dos menciones, ambas en la lección 12:

La población puede participar en la protección de la diversidad natural y cultural mediante tres tipos de acciones: conservar, transformar y eliminar... (SEP, 2014b, p. 112).

[La Ley General del Equilibrio Ecológico y la Protección del Ambiente] Promueve la participación de las personas en el cuidado ambiental (SEP, 2014b, p. 116).

Estas dos menciones recalcan la importancia de la participación para el bienestar de la comunidad a través del cuidado de la diversidad natural, lo cual nos parece un acierto. Además, esta lección presenta las fases de elaboración de un proyecto para procurar el bienestar social, lo cual podría fomentar la participación activa de las y los estudiantes.

En general, el libro contiene dos lecciones acerca de los derechos humanos, en las cuales se presenta información mayormente relacionada con los derechos económicos y no se hace alusión al derecho a la participación en alguna de las dos. La lección 20 (la última) destaca la importancia de la participación infantil en asuntos colectivos, pero, aunque es relevante que aparezca explícitamente esto en el texto, sería deseable que este derecho se hiciera presente como un proceso educativo a lo largo del libro.

\section{Sexto grado}

En diversos párrafos ubicamos 15 menciones del término participación y, de manera parecida al grado anterior, se presenta en especial el verbo sin conjugar (participar) y la forma nominal (participación); 11 se refieren a la dimensión política y 4, a la social-comunitaria. La estructura es igual que en el quinto grado: al final de cada lección hay un apartado denominado "Participemos" que ofrece indicaciones a las niñas y los niños para realizar diversas actividades. Estas menciones se analizan como parte de la dimensión pedagógica debido a que se esperan ciertos aprendizajes a partir de la realización de dichas actividades. 
Dimensión política

Al igual que en el grado anterior, las menciones del término hacen referencia a formas de participación del sistema democrático; tal es el caso de la elección por medio del voto y la representación como un modo de participación indirecta, como se muestra en los siguientes ejemplos:

Participar significa "tomar parte" de las decisiones y acciones que te interesan o que benefician al grupo al que perteneces [...]. Para que sea democrática, la participación se debe realizar mediante las formas que establece la ley (SEP, 2014c, p. 122).

La ciudadanía debe mantenerse informada para emitir un voto razonado y participar de manera efectiva (SEP, 2014c, p. 176).

Sin la participación ciudadana, la democracia no puede existir, por ello también es un derecho, que se puede ejercer en forma individual y ocasional, o bien, en grupos organizados alrededor de metas o planes de acción claros (SEP, 2014c, p. 147).

Participar es uno de estos derechos. Al ejercerlo fortaleces tu formación cívica y asumes tus responsabilidades como miembro de una sociedad. No necesitas esperar a tener la mayoría de edad para expresar tus opiniones sobre los asuntos que te interesan o te afectan... (SEP, 2014c, p. 123).

Las escuelas deben incluir actividades y mecanismos de participación democrática para su formación ciudadana (SEP, 2014c, p. 125).

Es importante destacar que, en este grado, a diferencia de los anteriores, se indica que la participación es un derecho y se complementa con la mención de algunos mecanismos de participación que se pueden y deben implementar en la escuela. Consideramos que, si bien en este grado se observa un concepto menos restringido de la participación, aún se circunscribe a la idea de que esta debe darse mediante los mecanismos que los adultos han determinado para el ejercicio de este derecho por parte de las niñas y los niños.

\section{Dimensión pedagógica}

En los párrafos no identificamos alguna mención que aludiera a algún aspecto de esta dimensión; sin embargo, y como ya señalamos, al finalizar cada lección hay un apartado titulado "Participemos", cuyas menciones se ubicaron en la dimensión pedagógica por las razones antes expuestas.

Una vez más, al analizar las actividades del apartado, las menciones pueden ajustarse al concepto de Trilla y Novella (2001) de participación simple, puesto que se limitan a intercambio de información y experiencias, exposición de trabajos elaborados previamente o a resolver o desarrollar una actividad. Como dijimos, la participación simple consiste en tomar parte de un proceso o actividad como espectador o ejecutante, sin que el niño o la niña hayan intervenido en su preparación ni en las decisiones sobre su contenido o desarrollo. Esto, insistimos, podría propiciar que las niñas y los niños construyan una noción de participación acotada y limitada (Ochoa, 2015; Castro, 2017; Pérez, 2017). 
Solo cuatro lecciones podrían entenderse como promotoras de una participación consultiva o proyectiva, pues, además de pedir la opinión de las y los estudiantes, se les invita a llevar a cabo un proyecto que, si bien no es un proyecto que surja de sus intereses y necesidades, plantea actividades en las que ellos podrían sugerir la dirección del proyecto.

Cabe especificar las condiciones que plantea la OEA respecto de los procesos participativos, entre estas el aprendizaje significativo a partir del cual las personas ven la realidad y se posicionan en ella (OEA/INN, 2010, p. 11); en este sentido, lo que observamos en estas actividades es una participación direccionada, que no necesariamente promueven en los niños y las niñas este posicionamiento en la realidad.

\section{Dimensión comunitaria}

En esta dimensión se localizaron cuatro menciones que refieren la importancia de la participación para resolver asuntos de interés común:

... Pero tienes el deber de participar en la atención de asuntos de interés común, de tal manera que contribuyas a mejorar tu entorno... (SEP, 2014c, p. 121).

... De esta manera, la niñez mexicana fortalecerá sus capacidades y valores ciudadanos al participar activamente en asuntos de interés común y en el mejoramiento de su entorno... (SEP, 2014c, p. 123).

Para resolver los problemas que afectan una comunidad se necesita de la participación de las personas que la integran (SEP, 2014c, p. 128).

... Por medio de la participación, las personas expresan sus ideas sobre el bienestar común, además de que esto contribuye a alcanzar sus ideales de dignidad y buen trato al aportar trabajo, ideas, recursos o tiempo a la atención a situaciones o problemas sociales... (SEP, 2014c, p. 176).

Podemos decir, de manera general, que a partir de la revisión del contexto en el que aparecen las menciones, así como por las actividades que se proponen, pareciera que, a pesar de que hay bloques que hacen explícito el concepto de participación, la idea que se deja ver es que no se considera el ejercicio de este derecho; es decir, si bien es importante que haya un hilo conductor a través del cual plantear el contenido y las actividades, sería deseable dar voz y protagonismo a las niñas y los niños, pues, por una parte, se explica que la participación solo es válida si se realiza con base en los lineamientos de una sociedad democrática y, por otra, las diferentes actividades y proyectos vienen ya dados; esto es, a menos que el profesor dé apertura a la opinión de las niñas y los niños acerca de temas que surjan del interés de ellos, el libro no da la pauta para que esto suceda.

\section{CONCLUSIONES}

Si partimos de la idea de que todas las escuelas son formadoras de ciudadanos como lo afirman Chaux, Lleras y Velásquez (2004), es oportuno preguntarnos qué tipo de ciudadanos se pretende formar, pues con base en la revisión realizada, observamos en los tres textos el predominio de la dimensión política al abordar con reiteración la democracia como la forma de gobierno sustentada en una participación indirecta 
mediante la representación. De esto inferimos, entonces, que la participación solo es válida en la medida que esté dada con base en los mecanismos que la misma democracia establece. No queda del todo claro el sentido de la democracia como modo de vida en el que los niños y las niñas puedan participar.

Por otro lado, aunque existen menciones, en particular en el libro de 60 grado, acerca de que el alumnado puede y debe participar, la mayor parte del contenido de los libros no pareciera reconocer este derecho por el énfasis que se hace a lo señalado en el párrafo anterior.

En relación con el tipo de participación que observamos, en su mayoría se podría ubicar como simple o consultiva, en la cual los niños y las niñas son meros ejecutores de indicaciones o son consultados sin que lo que opinen sea tomado en cuenta. Gran parte de las actividades que se proponen van en este sentido: contestar preguntas, comentar entre pares, exponer trabajos elaborados previamente, comparar información, entre otras, y son pocas las oportunidades en las que el alumnado podría proponer libremente. Por ejemplo, hay una actividad que indica realizar una campaña para combatir la discriminación; en ella no se da la oportunidad de que los niños y las niñas propongan otro medio o mecanismo para enfrentar esta problemática. Esto nos hace pensar que el concepto de participación que se promueve en el libro sigue siendo acotado y restringido, lo cual podría propiciar que las niñas y los niños construyan una noción de participación ceñida a seguir las instrucciones de los adultos, como lo han demostrado estudios anteriores (Ochoa, 2015; Castro, 2017; Pérez, 2017).

Consideramos la participación como un derecho que permite fomentar conocimientos, habilidades y actitudes necesarias para el desarrollo personal y social; sin embargo, para que esto se dé es indispensable que las instituciones educativas generen las condiciones para favorecer procesos participativos: reconocimiento del derecho, clima participativo, vínculo, encuentro, oportunidades y mecanismos (Trilla y Novella, 2001; OEA/INN, 2010), de tal manera que el libro de texto, al ser un componente central en la vida cotidiana de la institución escolar, coadyuve al establecimiento de estas condiciones.

Si bien es cierto que este estudio se limita a interpretar la información que se presenta en una asignatura de tres grados escolares de nivel primaria, es relevante advertir que, como ya se ha señalado en muchos casos, el libro es la guía de las prácticas pedagógicas, lo cual nos lleva a pensar que si los docentes no tienen una mirada de la participación como un proceso educativo, la información y las actividades son poco significativas y no se rebasa el enfoque prescriptivo, el cual se pretende superar a partir de la reforma curricular de 2011. Por ello, se hace necesario indagar la práctica docente basada en los libros analizados.

\section{Agradecimiento}

Agradecemos al fondo sectorial de investigación SEP/SEB/Conacyt 2015 el apoyo para la realización de esta investigación

\section{REFERENCIAS BIBLIOGRÁFICAS}

Álvarez, L. (1982). Justo Sierra y la obra educativa en el porfiriato. En F. Solana (coord.). Historia de la educación pública en México. México: Fondo de Cultura Económica. Bardin, L. (2002). El análisis de contenido. Madrid: Akal. 
Bolívar, A. (2007). Educación para la ciudadanía. Algo más que una asignatura. Barcelona: Graó.

Boqué, M. C., Pañellas, M., Alguacil, M. y García, L. (2014). La cultura de paz en la educación para la ciudadanía y los derechos humanos en los libros de texto de educación primaria. Perfiles Educativos, vol. 36, núm. 146. Recuperado de http:// www.iisue.unam.mx/perfiles/articulo/2014-146

Castro, J. (2017)._Formación de valores para la convivencia democrática mediante el desarrollo de la participación infantil: un proyecto de aprendizaje basado en el servicio en una escuela de educación primaria. Tesis para obtener el grado de maestro en Educación para la Ciudadanía. México: Universidad Autónoma de Querétaro.

Cerda, A., Loreto, M., Magendzo, A., Santacruz, E. y Varas, R. (2004). El complejo camino de la formación ciudadana: una mirada a las prácticas docentes. Chile: LOM/PIIE.

Chaux, E., Lleras, J. y Velásquez, A. (2004) (comps.). Competencias ciudadanas: de los estándares al aula: una propuesta de integración a las áreas académicas. Bogotá: Ministerio de Educación/Universidad de los Andes, Facultad de Ciencias Sociales, Departamento de Psicología y Centro de Estudios Socioculturales e Internacionales/Ediciones Uniandes.

Conde, S. (2011). Entre el espanto y la ternura. Formar ciudadanos en contextos violentos. México: Cal y Arena.

Consejo de Europa (2004). División para la ciudadanía y los derechos humanos. Recuperado de http://www.coe.int/T/E/Cultural_Co-operation/education/E.D.C/.

Corona, S. y De la Peza, C. (2000). La educación ciudadana a través de los libros de texto. Sinéctica, núm. 16, pp. 16-30. Recuperado de https://sinectica.iteso.mx/ index.php/SINECTICA/article/view/399/392

Corona, Y. y Del Río, N. (2005) (coords.). Antología del Diplomado Derechos de la Infancia, Infancia en Riesgo. México: UAM/Universidad de Valencia.

Corona, S. y Le Mûr, R. (2016). Racismo en la imagen de los indígenas en los libros de texto gratuitos (2012-2015). Comunicación y Sociedad, núm. 28, pp. 11-33. Recuperado de http://www.revistascientificas.udg.mx/index.php/comsoc/article/ view/5419/5687.

De la Caba, A. y López, R. (2005). Actividades de participación y desarrollo de competencias de ciudadanía en los libros de texto de educación primaria de la comunidad autónoma vasca. Revista de Educación, núm. 336, pp. 377-396. Recuperado de http://www.revistaeducacion.mec.es/re336/re336_20.pdf

Escudero, A. y Farías, D. (2015). La noción de ciudadanía en los libros de texto de educación básica. Análisis desde la teoría del actor-red. Sinéctica, núm. 45. Recuperado de https://sinectica.iteso.mx/index.php/SINECTICA/article/view/591/584

Eurydice (2005). La educación para la ciudadanía en el contexto escolar europeo. Comisión Europea.

Fierro, C. (2011). Cívica y ética: ¿asignatura elusiva o eludida? En R. Barriga (ed.). Entre paradojas: a 50 años del libro de texto gratuito. México: El Colegio de México/ SEP/Conaliteg.

Gallardo, P. (2009). Educación ciudadana y convivencia democrática. SIPS- Revista Interuniversitaria de Pedagogía Social, núm. 16, tercera época, pp. 119-133. Recuperado de https://recyt.fecyt.es/index.php/PSRI/article/view/36953/20519

Gómez, A. y Zurita, U. (2012). La escuela mexicana y la formación ciudadana. Notas para su estudio. México. Educación 2000, núm. 59, pp. 209-243. Recuperado de http://revistas.lasalle.edu.co/index.php/ap/article/viewFile/59/15 
Gutiérrez, J. (2007). Educación: formación cívica y ética. México: Cal y Arena.

Hart, R. (1993). La participación de los niños: de una participación simbólica a una participación auténtica. Colombia: UNICEF, serie Ensayos Innocenti, 4.

Latapí, P. (2002). La moral regresa a la escuela. Una reflexión sobre la ética laica en la educación mexicana. México: UNAM.

Latapí, P. (1993). Reflexiones sobre la justicia en la educación. Revista Latinoamericana de Estudios Educativos, vol. XXIII.

Marco, B. (2002). Educación para la ciudadanía: un enfoque basado en el desarrollo de competencias transversales. Madrid: Narcea.

Martín, X. (2010). La educación para la ciudadanía en la escuela. En J. Puig (coord.). Entre todos. Compartir la educación para la ciudadanía. Barcelona: Horsori/Universitat de Barcelona.

Mokwena, S. (1993). Youth participation, development and social change. A synthesis of care concepts and issues. Baltimore: International Youth Foundation, Learning Department.

Novella, A. (2011). La participación infantil: concepto dimensional en pro de la autonomía ciudadana. Actas del XII Congreso de Teoría de la Educación. Barcelona: Universitat de Barcelona.

Ochoa, A. (2015). Concepciones sobre participación de niñas, niños y adolescentes: su importancia en la construcción de la convivencia escolar. Cultura, Educación y Sociedad, vol. 6, núm. 2. Recuperado de http://revistascientificas.cuc.edu.co/ index.php/culturaeducacionysociedad/article/view/840

OEA/INN (2010). Menú de indicadores y sistema de monitoreo del derecho a la participación de niños, niñas y adolescentes. Montevideo. Recuperado de http://www. iin.oea.org/IIN2011/documentos/Menu_Indicadores_y_sistema_monitoreo.pdf.

ONU (2009). El derecho del niño a ser escuchado. Observación General núm. 12 (CRC/C/GC/12). Ginebra: Comité de los Derechos del Niño.

ONU (1989). Convención sobre los Derechos del Niño. París. Recuperado de Disponible en: http://www.ohchr.org/SP/Professionallnterest/Pages/CRC.aspx

Pérez, A. (1995). Las funciones sociales de la escuela: de la reproducción a la reconstrucción crítica del conocimiento y la experiencia. En J. Gimeno y A. Pérez (coords.). Comprender y transformar la enseñanza. Madrid: Morata.

Pérez, L. (2017). La participación infantil como elemento fundamental de la convivencia democrática: una experiencia de aprendizaje-servicio en educación secundaria. Tesis para obtener el grado de maestro en Educación para la Ciudadanía, Universidad Autónoma de Querétaro, México.

Rockwell, E. (1997). De huellas, bardas y veredas: una historia cotidiana en la escuela. En E. Rockwell (coord.). La escuela cotidiana. México: Fondo de Cultura Económica.

Schmelkes, S. (2011). Tendencias generales de las temáticas abordadas en la formación cívica y ética. En A. Alba et al. (coords.). La formación cívica y ética en la educación básica: retos y posibilidades en la sociedad globalizada. México: SEP.

SEP (2011). La formación cívica y ética en la educación básica: retos y posibilidades en el contexto de la sociedad globalizada. México: SEP-Subsecretaría de Educación Básica-Dirección General de Desarrollo Curricular/Escuela Normal Superior de México.

SEP (2014a). Formación cívica y ética. Cuarto grado. Mexico: Conaliteg.

SEP (2014b). Formación cívica y ética. Quinto grado. Mexico: Conaliteg. 
SEP (2014c). Formación cívica y ética. Sexto grado. Mexico: Conaliteg.

Tapia, E. (2003). Socialización política y educación cívica en los niños. México: Instituto Mora.

Trilla, J. y Novella, A. (2001). Educación y participación social en la infancia. Revista Iberoamericana de Educación, núm. 26, pp. 137-164. Recuperado de http://www. rieoei.org/rie26a07.htm

Van Dijk, S., Menéndez, M. J. y Gómez, A. (2006). Participación infantil, un marco para pensar la noción de la formación. México: Save the Children. Recuperado de http:// www.savethechildrenmexico.org.mx/website2008/pdf/Part_\% 20Infantil.pdf

Vázquez, J. (1975). Nacionalismo y educación en México. México: El Colegio de México. Villa, L. (2011) Reformas educativas y libros de texto gratuitos. En R. Barriga (ed.). Entre paradojas: a 50 años de los libros de texto gratuitos. México: El Colegio de México/SEP/Conaliteg. 